\title{
Spot urine iodine levels below the WHO recommendation are not related to impaired thyroid function in healthy children and adolescents
}

\author{
Tillmann Wallborn ${ }^{1,2} \cdot$ Mandy Vogel $^{2} \cdot$ Antje Kneuer $^{3} \cdot$ Michael Thamm $^{3} \cdot$ Katalin Dittrich $^{1} \cdot$ Wieland Kiess $^{1,2}$. \\ Jürgen Kratzsch ${ }^{4}$
}

Received: 9 November 2019 / Accepted: 28 April 2020 / Published online: 11 May 2020

(c) The Author(s) 2020

\begin{abstract}
Purpose Iodine deficiency in childhood and adolescence may lead to later thyroid dysfunction, stunted growth and cognitive impairment. The World Health Organization (WHO) has issued recommended age-dependent urine iodine concentration targets, but a critical threshold beyond which clinical sequelae are to be expected remains undefined. Our study aimed to investigate spot urine iodine concentration in a typical Central European cohort of children and adolescents, and consider the implications of these values in regard to laboratory parameters for evaluating thyroid function.

Methods Using the Sandell-Kolthoff method, spot urine iodine concentration was measured cross-sectionally from 1802 healthy children and adolescent in the age range of 0.25-18 years within the LIFE-Child epidemiological study based in and around the city of Leipzig (Germany). Additionally, serum thyroid biomarkers of these subjects were measured and correlated to urine iodine levels.

Results In our cohort, $61.39 \%$ of boys and $65.91 \%$ of girls had an iodine level of $<100 \mu \mathrm{g} / \mathrm{L}$ ( $57 \%, 67 \%, 65 \%$ of the age groups $0-5,6-12$ and $13-18$ years), the median iodine excretion was $86 \mu \mathrm{g} / \mathrm{L}$ in boys and $80 \mu \mathrm{g} / \mathrm{L}$ in girls. The iodine levels revealed no significant correlation with the thyroid biomarkers TSH, FT4 and FT3. Moreover, iodine values revealed no correlation with levels of antibodies against thyroid peroxidase or thyroglobulin.

Conclusion In our cohort of children and adolescents, the relatively high number of iodine levels below the WHO recommendation appears not to be related to clinical or subclinical thyroid diseases in the respective participants.
\end{abstract}

Keywords Iodine $\cdot$ Thyroid $\cdot$ Urine $\cdot$ Children $\cdot$ TSH $\cdot$ FT4 $\cdot$ FT3

Tillmann Wallborn

tillwallborn@gmail.com

1 University Hospital for Children and Adolescents, University of Leipzig, 04103 Leipzig, Germany

2 LIFE Research Center for Civilization Diseases, University of Leipzig, Leipzig, Germany

3 Department of Epidemiology and Health Monitoring, Robert Koch Institute, 13302 Berlin, Germany

4 Institute of Laboratory Medicine, Clinical Chemistry and Molecular Diagnostics, University Hospital, Leipzig, Germany

\section{Introduction}

The World Health Organization (WHO) recommended daily intake of iodine for children and adolescents of $90-150 \mu \mathrm{g} /$ day, depending on age $[1,2]$. Recommendations given from German authorities were in a comparable range of $40-200 \mu \mathrm{g} /$ day [3]. Numerous clinical studies suggested that insufficient iodine intake can lead to hypothyroidism with thyroid enlargement (goiter), stunted growth, cognitive impairment (especially of the fetal brain), an increased risk of stillbirth, or a number of other typical clinical signs [4]. Accordingly, iodine deficiency may be considered one of the most significant single causes of preventable brain damage in the world [5].

In recent years, iodine fortification of foodstuffs has been used worldwide as a key strategy in addressing the problem of iodine deficiency. By 2011, the number of iodine-deficient 
countries had decreased from 54 to 32 as compared to the year 2003, while the number of countries with adequate supply increased from 67 to 105 [6]. Despite this positive development, it has been hypothesized that $29 \%$ of the world's population has an insufficient iodine intake [7]. This problem is not only a question of socioeconomic development. Even in a number of high-income countries (e.g. in Europe) the risk of iodine deficiency is higher than in some poorer regions of the world [8-10]. The WHO reported an improved iodine supply in European children, based on a decrease in levels of iodine deficiency from $60 \%$ of children in 2003 to $44 \%$ in 2012 [4, 7, 11]. In 2005, the WHO suggested that the state of iodine nutrition be reported every three years (WHA58.24), but global data about progress in resolving iodine deficiency are incomplete. The most recent report about the prevalence of iodine deficiency in Germany was only published in 2006 [11]. A nationwide study showed $41 \%$ of children and adolescents with suboptimal iodine intake in the period from 2003 to 2006 with the highest portion of both, insufficient and excessive iodine intake in the age group 0-2 years [12]. This is a significantly higher percentage than the $27 \%$ reported by a former survey in Germany from 1999 [13]. The observation of increased levels of iodine deficiency agrees with another German nationwide food habit survey ("Nationale Verzehrstudie II") carried out in 2005 and 2006. This study revealed that a high percentage of adolescents- $41.1 \%$ of adolescent boys and $73.1 \%$ of adolescent girls - had a daily iodine intake of less than $200 \mu \mathrm{g}[14]$.

To date, a number of different methods have been described for diagnosing iodine deficiency. In the past, thyroid function impairment was investigated by palpation of the thyroid gland or by the detection of increased thyroid volume via ultrasound. However, these methods were limited in terms of both sensitivity and specificity, especially in cases of subclinical diseases [15]. Moreover, both methods were susceptible to severe inter-observer error. Thus, the WHO recommended the measurement of iodine concentration in spot urine samples (SUIC) as an objective method for estimating iodine intake [2]. SUIC appears to be an effective indicator of recent dietary iodine intake since $>92 \%$ of ingested iodine is absorbed and $>90 \%$ is excreted within 24-48 h [15]. Since iodine excretion generally demonstrated a large intra-day variance, more accurate results can be obtained by collecting urine over a 24 -h period. However, this method was not practicable in large field studies, especially those involving infants and children [15]. Surveys of iodine status have usually been carried out with cohorts of school children because they are easily accessible and representative for the general population [13]. The WHO provided the following reference concentration ranges for median SUIC: severe iodine deficiency $<20 \mu \mathrm{g} / \mathrm{L}$, moderate iodine deficiency $20-49 \mu \mathrm{g} / \mathrm{L}$, mild iodine deficiency
50-99 $\mu \mathrm{g} / \mathrm{L}$, adequate iodine nutrition 100-199 $\mu \mathrm{g} / \mathrm{L}$, above requirements 200-299 $\mu \mathrm{g} / \mathrm{L}$, excessive (posing risk of adverse health consequences) $\geq 300 \mu \mathrm{g} / \mathrm{L}$ [2]. According to the WHO, in a population not characterized by iodine deficiency, the median SUIC should be between 100-299 $\mu \mathrm{g} / \mathrm{l}$ in children, with no more than $20 \%$ of children exhibiting an SUIC below $50 \mu \mathrm{g} / \mathrm{L}$. The median was used instead of the mean because the distribution of SUIC levels is often skewed towards higher levels [16].

Although the pathophysiological relationship between iodine deficiency and thyroid dysfunction has been clearly established, no critical threshold has been derived from a population-based SUIC sample below which we can say there is a high probability of developing thyroid dysfunction. Moreover, various studies have indicated that an excessive intake of iodine may increase the incidence of autoimmune thyroiditis [17]. High levels of iodine may modulate the immune system and cause the destruction of thyrocytes. In consequence, higher rates of hypothyroidism can be found in regions with high iodine intake. An association between high SUIC (>300 g/L) and autoimmune thyroiditis (thyroid peroxidase antibodies) has also been found in children [18]. The aim of our study was, first, to investigate SUIC levels among children and adolescents in the LIFE Child study based in Leipzig (Germany) and, second, to consider whether these SUIC values might show any correlation with parameters of thyroid function in our cohort.

\section{Subjects}

Our cohort of infants, children and adolescents was recruited from among the participants of the LIFE Child study in Leipzig (clinical trial number NCT02550236). This study is a prospective, longitudinal health survey initiated by the Hospital for Children and Adolescents at the University of Leipzig (Germany). The study is open to all children and adolescents (and their parents) and includes medical and psychological examinations and questionnaires. Age of study participants was between 3 months and 17 years of age (median 9.4 years). In terms of their anthropometric data, our cohort was representative of the general population (mean height-SDS 0.12, mean BMI-SDS 0.13). Participants are requested to come without having eaten breakfast to the study clinic. After a medical examination, blood and spot urine samples were withdrawn via urine cup, urine potty or urine bag. A detailed description of the LIFE Child study, including the recruitment process and data acquisition, is available $[19,20]$. The study was approved by the Ethics Committee of the University of Leipzig (Reg. No. 264-1019042010). Fully informed, written consent was obtained from all participants and their parents after a full explanation of the purpose and nature of all procedures used. All 
of the samples and data on which our study is based were collected between 11/2013 and 08/2015 in a cross-sectional setting. One blood as well as one urine sample of the first visit of each participant was included in the study archive. An aliquot of the total urine sample of each study subject was stored at $-80^{\circ} \mathrm{C}$ in a local biobank. Samples were sent to the analyzing laboratory (Robert Koch Institute, Central Epidemiological Laboratory, Berlin) and were stored at $-40{ }^{\circ} \mathrm{C}$ before analysis.

In total, we included 1982 subjects with completed questionnaires and available spot urine samples. Children and adolescents with endocrine, metabolic, renal, cardiac, gastrointestinal or muscular diseases were excluded. Moreover, subjects who were taking medication (e.g. thyroid hormones or antibiotics) or whose medical examination produced abnormal findings (fever, goiter) were also excluded. The remaining sample comprised of 1802 individual subjects.

\section{Methods}

Inductively coupled plasma mass spectrometry (ICP-MS) is the current gold standard for iodine measurement but this method is prohibitively complex and costly [21]. Therefore, in line with the WHO recommendation, SUIC values were measured using the Sandell-Kolthoff method [2]. To remove interfering substances, a $500 \mu \mathrm{L}$ sample was mixed with $800 \mu \mathrm{L}$ ammonium peroxydisulfate $(1 \mathrm{~mol} / \mathrm{L})$ and $200 \mu \mathrm{L}$ sodium hydroxide $(0.875 \mathrm{~mol} / \mathrm{L})$ and heated for $60 \mathrm{~min}$ to $95 \pm 2{ }^{\circ} \mathrm{C}$ (thermoblock, Rotilabo ${ }^{\circledR}$ Block-Heater H250, Roth, Karlsruhe, Germany) [22]. Thereafter, samples were cooled to room temperature and transferred to the analyzer (Cobas Mira plus, Roche, Basel, Switzerland). An aliquot of $80 \mu \mathrm{L}$ of digested sample was mixed with $200 \mu \mathrm{L}$ arsenious acid $(0.0253 \mathrm{~mol} / \mathrm{L})$ and after $168 \mathrm{~s}$, the Sandell-Kolthoff reaction was initiated using $50 \mu \mathrm{L}$ Cerium(IV)-sulfate $(0.0378 \mathrm{~mol} / \mathrm{L})$. The detection range of the method included SUIC values from $7.5 \mu \mathrm{g} / \mathrm{L}$ up to $419 \mu \mathrm{g} / \mathrm{L}$. The method was cross-validated with ICP-MS [21]. All other laboratory parameters were determined using a Cobas automated analyzer (Roche, Mannheim): creatinine was measured by enzymatic method, TSH (thyrotropin), FT3 (free triiodthyronine), FT4 (free thyroxine), TPO-Ab (thyroid peroxidase antibodies) and TG-Ab (thyroglobulin antibodies) were determined by the electrochemiluminescence method (ECLIA). Reference ranges for TSH, FT3 and FT4 were established by an in-house study [23]. To investigate correlations between thyroid biomarkers, creatinine and iodine concentrations, age and gender-adjusted standard deviation scores (SDS) were determined for TSH, FT3 and FT4.

Creatinine is an indicator of the individual's hydration status. For creatinine adjustment of SUIC the ratio of urinary iodine to creatinine (creatinine-corrected iodine, CCUI) was calculated. CCUI values were converted to age- and sexadjusted SDS.

Descriptive statistics were determined in terms of median and interquartile range for iodine, TPO-Ab and TG-Ab as well as of mean and standard deviation for TSH, FT3 and FT4. Univariate relationships according to Pearson were estimated between iodine status and thyroid function. Empirical density was estimated using a Gaussian kernel. Group differences were tested applying 2-sample $t$ tests. Measurement values were converted to standard deviation scores (SDS) using the extended LMS-method as implemented in the gamlss package [24]. All statistical analysis and data visualization were performed using the statistical language $\mathrm{R}$ [25]. The significance level was set to alpha $=0.05$.

\section{Results}

\section{Spot urine iodine levels}

The median SUIC in our cohort was $86.3 \mu \mathrm{g} / \mathrm{L}$ for boys $(n=1010)$ and $80.0 \mu \mathrm{g} / \mathrm{L}$ for girls $(n=792)$ without a significant difference between gender (Table 1; Fig. 1). The highest levels of iodine were measured in the first year of life with a non-significantly higher median SUIC of $112.3 \mu \mathrm{g} / \mathrm{L}$ in boys compared to $106.0 \mu \mathrm{g} / \mathrm{L}$ in girls. Thereafter, SUIC values present a trend to lower levels, especially in boys. The correlation between age and iodine was not significant in our correlation model, but significant in the linear regression model. Also interquartile ranges were higher in the first year of age with a negative SUIC trend during childhood, again especially in boys. In our cohort in total $61.39 \%$ of boys and $65.91 \%$ of girls presented iodine values below $100 \mu \mathrm{g} / \mathrm{L}$, the threshold for iodine deficiency according to the WHO classification (Table 2). Percentage of subjects with severe iodine deficiency $(<20 \mu \mathrm{g} / \mathrm{L})$ was $4.06 \%$ in boys and $4.42 \%$ in girls. Only 13 participants $(0.72 \%)$ showed iodine levels in the "excessive" range of $>300 \mu \mathrm{g} / \mathrm{L}$.

\section{Creatinine adjusted iodine spot levels}

Low SUIC values were associated with low creatinine levels (Fig. 2). Therefore, age- and sex-specific CCUI values were calculated. The data indicated a significant correlation between the two parameters (iodine SDS alone and CCUISDS) although the correlation coefficient was low $(r=0.15$, $p<0.001$; Table 3).

\section{lodine deficiency and thyroid parameters TSH, FT3 and FT4}

To investigate the impact of SUIC on thyroid function we analyzed serum thyroid biomarkers TSH, FT3 and FT4 of 


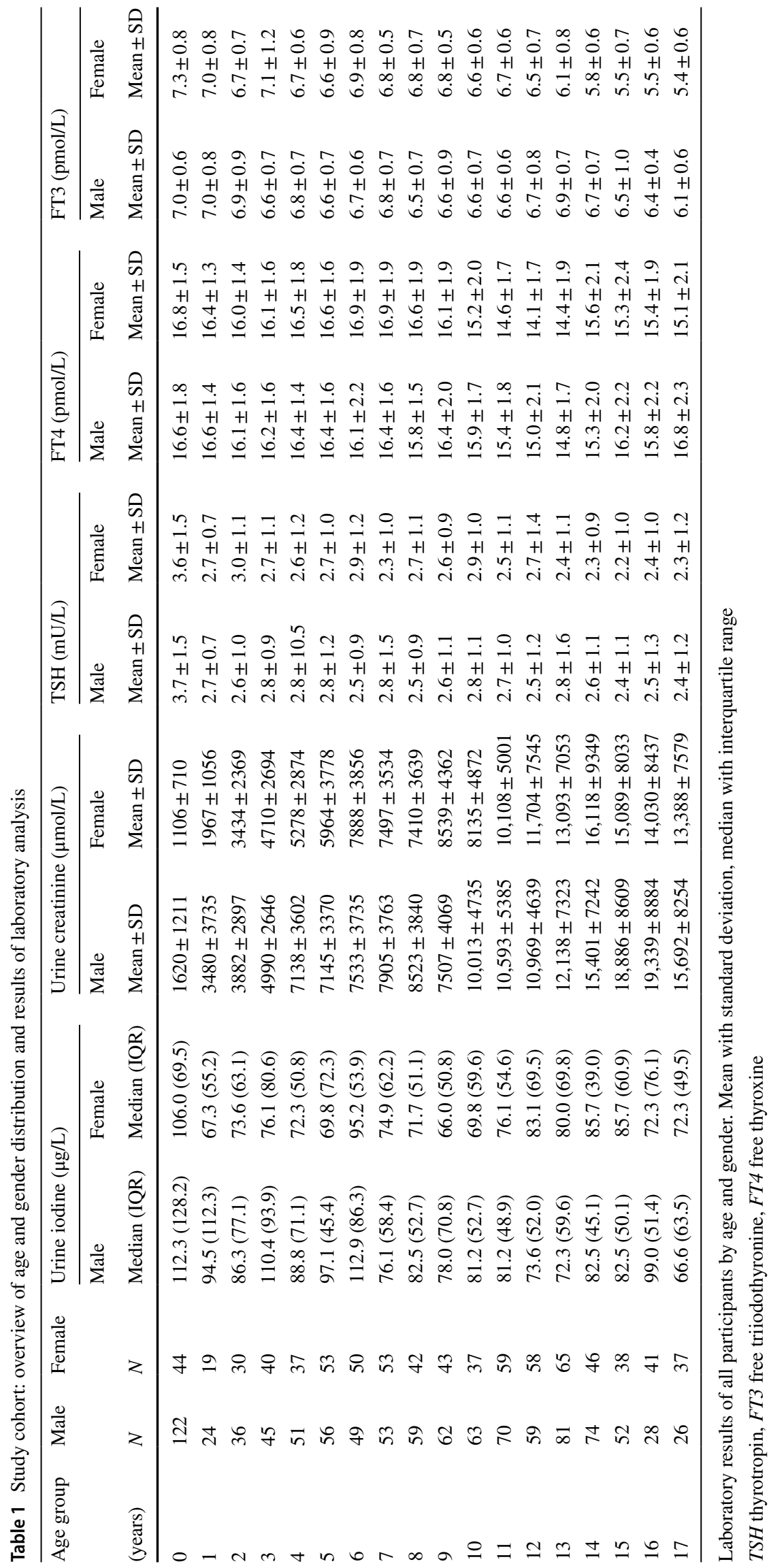




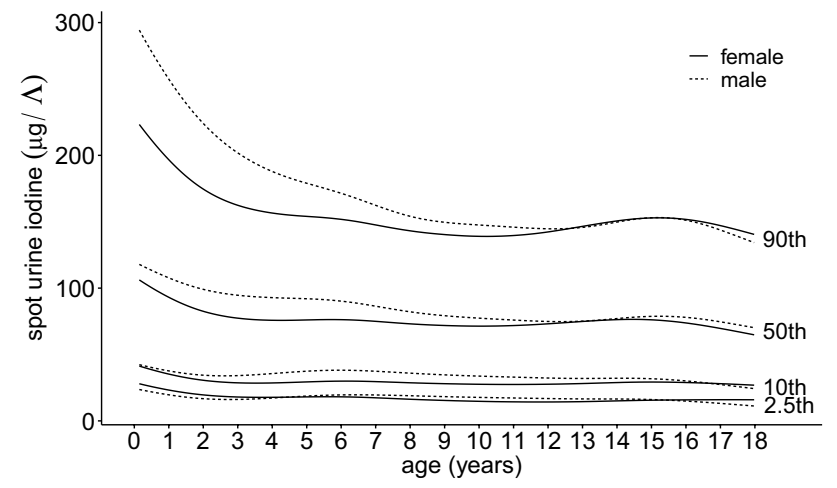

Fig. 1 Spot urine iodine concentration of all participants by age and gender with percentiles

all participants (Table 1). All three biomarkers, as well as urine creatinine levels, presented a typical age-dependent distribution: TSH decreased during childhood with highest levels in the first year and lowest levels at the age of 17 years. FT3 and FT4 also decreased in early childhood, but thereafter, FT4 presented a small rise in older adolescents and FT3 showed a peak in boys at the age of 13 years. Urine creatinine increased significantly with increasing age. Pearson correlation coefficients were calculated between the SDS values for TSH, FT3, FT4 and those for SUIC and CCUI (Table 3). Only the association between FT3-SDS and SUIC was statistically significant.

Moreover, SUIC values with low $(<-1.28)$, moderate $(-1.28$ to +1.28$)$ and high $(>+1.28)$ SDS were compared in respect to levels of TSH (Fig. 3), FT3 and FT4 (Fig. 4) in the same participants. Again, in relation to thyroid biomarker levels, no significant difference was identified between subjects with low, moderate and high SUIC.

In our cohort, $3.7 \%$ of participants presented increased $(n=59$, subclinical hypothyroid) or decreased TSH $(n=7$, subclinical hyperthyroid) compared with reference values from an in-house study [23]. Of course, this number is very low but in the interests of control we compared these subjects with the whole cohort. SUIC-SDS values of -0.02 $(p=0.85)$ and $+0.52(p=0.19)$ suggest that these subjects do not present any significant difference in this regard. Finally, in our study, 24 participants were excluded due to the identification of mild goiter during the medical examination. But even with these individuals, when the SUIC data are compared with those for the whole cohort, the values

Table 2 Distribution of spot urine iodine levels of all participants by age and gender according to the WHO classification

\begin{tabular}{|c|c|c|c|c|c|c|c|c|c|c|c|c|}
\hline \multirow{2}{*}{$\begin{array}{l}\text { Iodine }(\mu \mathrm{g} / \mathrm{L}) \\
\text { Age group (years) }\end{array}$} & \multicolumn{2}{|l|}{$<20$} & \multicolumn{2}{|c|}{$20-49$} & \multicolumn{2}{|c|}{$50-99$} & \multicolumn{2}{|c|}{$100-199$} & \multicolumn{2}{|c|}{$200-299$} & \multicolumn{2}{|l|}{$\geq 300$} \\
\hline & Male & Female & Male & Female & Male & Female & Male & Female & Male & Female & Male & Female \\
\hline \multicolumn{13}{|c|}{$\%$ of children in the corresponding age group } \\
\hline 0 & 2.5 & 0.0 & 9.8 & 9.1 & 35.2 & 36.4 & 27.9 & 38.6 & 18.0 & 13.6 & 6.6 & 2.3 \\
\hline 1 & 8.3 & 5.3 & 20.8 & 31.6 & 25.0 & 36.8 & 37.5 & 21.1 & 8.3 & 5.3 & 0.0 & 0.0 \\
\hline 2 & 16.7 & 3.3 & 11.1 & 33.3 & 30.6 & 33.3 & 36.1 & 26.7 & 5.6 & 3.3 & 0.0 & 0.0 \\
\hline 3 & 2.2 & 5.0 & 11.1 & 20.0 & 31.1 & 37.5 & 51.5 & 32.5 & 2.2 & 5.0 & 2.2 & 0.0 \\
\hline 4 & 0.0 & 0.0 & 17.6 & 21.6 & 43.1 & 51.4 & 37.3 & 24.3 & 2.0 & 2.7 & 0.0 & 0.0 \\
\hline 5 & 1.8 & 3.8 & 12.5 & 22.6 & 41.1 & 41.5 & 39.3 & 28.3 & 3.6 & 3.8 & 1.8 & 0.0 \\
\hline 6 & 2.0 & 0.0 & 10.2 & 16.0 & 32.7 & 36.0 & 44.9 & 48.0 & 10.2 & 0.0 & 0.0 & 0.0 \\
\hline 7 & 5.7 & 9.4 & 18.9 & 17.0 & 45.3 & 43.4 & 28.3 & 30.2 & 1.9 & 0.0 & 0.0 & 0.0 \\
\hline 8 & 1.7 & 2.4 & 16.9 & 23.8 & 47.5 & 47.6 & 32.2 & 23.8 & 1.7 & 2.4 & 0.0 & 0.0 \\
\hline 9 & 8.1 & 2.3 & 25.8 & 27.9 & 33.9 & 44.2 & 29.0 & 23.2 & 3.2 & 2.3 & 0.0 & 0.0 \\
\hline 10 & 4.8 & 8.1 & 12.7 & 32.4 & 49.2 & 29.7 & 27.0 & 24.3 & 6.3 & 5.4 & 0.0 & 0.0 \\
\hline 11 & 1.4 & 6.8 & 20.0 & 20.3 & 47.1 & 45.8 & 30.0 & 27.1 & 1.4 & 0.0 & 0.0 & 0.0 \\
\hline 12 & 5.1 & 10.3 & 20.3 & 17.2 & 49.2 & 36.2 & 22.0 & 34.5 & 3.4 & 1.7 & 0.0 & 0.0 \\
\hline 13 & 6.2 & 4.6 & 23.5 & 27.7 & 40.7 & 27.7 & 27.2 & 40.0 & 2.5 & 0.0 & 0.0 & 0.0 \\
\hline 14 & 1.4 & 2.2 & 18.9 & 17.4 & 44.6 & 43.5 & 32.4 & 34.8 & 2.7 & 2.2 & 0.0 & 0.0 \\
\hline 15 & 3.8 & 2.6 & 19.2 & 15.8 & 46.2 & 39.5 & 23.1 & 39.5 & 5.8 & 2.6 & 1.9 & 0.0 \\
\hline 16 & 0.0 & 9.8 & 7.1 & 22.0 & 42.9 & 36.6 & 50.0 & 29.3 & 0.0 & 0.0 & 0.0 & 2.4 \\
\hline 17 & 11.5 & 0.0 & 26.9 & 35.1 & 26.9 & 43.2 & 34.6 & 18.9 & 0.0 & 2.7 & 0.0 & 0.0 \\
\hline All age groups & 4.1 & 4.4 & 16.7 & 22.1 & 40.6 & 39.4 & 32.3 & 31.2 & 5.2 & 2.7 & 1.1 & 0.3 \\
\hline
\end{tabular}

Spot urine iodine distribution of all participants sorted by the WHO classified categories $(<20 \mu \mathrm{g} / \mathrm{L}$ severe iodine deficiency, $20-49 \mu \mathrm{g} / \mathrm{L}$ moderate iodine deficiency, 50-99 $\mu \mathrm{g} / \mathrm{L}$ mild iodine deficiency, 100-199 $\mu \mathrm{g} / \mathrm{L}$ adequate iodine nutrition, 200-299 $\mu \mathrm{g} / \mathrm{L}$ above requirements, $\geq 300 \mu \mathrm{g} / \mathrm{L}$ excessive). Percentage refers to the number of children in the corresponding age group. Last line presents percentage of all children (every age) in the corresponding WHO category. In summary $61.2 \%$ of boys and $65.9 \%$ of girls presented with spot urine iodine concentration below $100 \mu \mathrm{g} / \mathrm{L}$ 


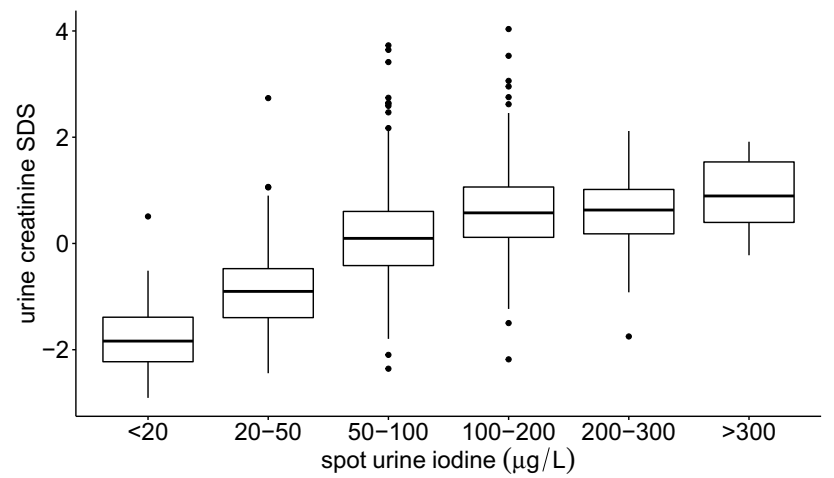

Fig. 2 Creatinine SDS and spot urine iodine levels of all participants according to the WHO classification. Creatinine-SDS were calculated for each age group and compared to WHO iodine categories. Participants with higher urine creatinine levels also presented higher iodine levels

Table 3 Pearson correlation coefficient and linear regression model calculation for age, iodine status and thyroid function of all participants

\begin{tabular}{|c|c|c|c|c|}
\hline \multirow[t]{2}{*}{ Compared data } & \multicolumn{2}{|c|}{$\begin{array}{l}\text { Correlation } \\
\text { coefficient }\end{array}$} & \multicolumn{2}{|c|}{ Linear regression } \\
\hline & Corr & $p$ & beta & $p$ \\
\hline Age vs. SUIC & -0.19 & $<0.001$ & -0.02 & $<0.001$ \\
\hline Age vs. SUIC (only > 1 year) & -0.08 & 0.33 & -0.006 & 0.006 \\
\hline Age vs. TSH & -0.20 & $<0.001$ & -0.77 & $<0.001$ \\
\hline Age vs. fT3 & -0.32 & $<0.001$ & -1.82 & $<0.001$ \\
\hline Age vs. fT4 & -0.24 & $<0.001$ & -0.56 & $<0.001$ \\
\hline Age vs. creatinine (urine) & 0.62 & $<0.001$ & $<0.001$ & $<0.001$ \\
\hline SUIC-SDS vs. TSH-SDS & -0.04 & 0.11 & -0.04 & 0.11 \\
\hline SUIC-SDS vs. fT3-SDS & -0.07 & 0.02 & -0.05 & 0.06 \\
\hline SUIC-SDS vs. fT4-SDS & -0.01 & 0.63 & -0.01 & 0.74 \\
\hline $\begin{array}{l}\text { SUIC-SDS vs. SUIC/creatinine- } \\
\text { SDS }\end{array}$ & 0.15 & $<0.001$ & 0.08 & $<0.001$ \\
\hline $\begin{array}{l}\text { SUIC/creatinine-SDS vs. TSH- } \\
\text { SDS }\end{array}$ & -0.01 & 0.80 & -0.01 & 0.79 \\
\hline $\begin{array}{l}\text { SUIC/creatinine-SDS vs. fT3- } \\
\text { SDS }\end{array}$ & 0.01 & 0.75 & 0.03 & 0.58 \\
\hline $\begin{array}{l}\text { SUIC/creatinine-SDS vs. fT4- } \\
\text { SDS }\end{array}$ & 0.02 & 0.93 & 0.05 & 0.36 \\
\hline
\end{tabular}

Calculated bivariate correlation coefficient (corr) with significance level $(p)$ and linear regression model. SDS values were calculated age and gender dependent

SUIC spot urine iodine concentration, TSH thyrotropin, FT3 free triiodothyronine, FT4 free thyroxine

are close to the median level and largely comparable $(+0.08$ SUI-SDS).

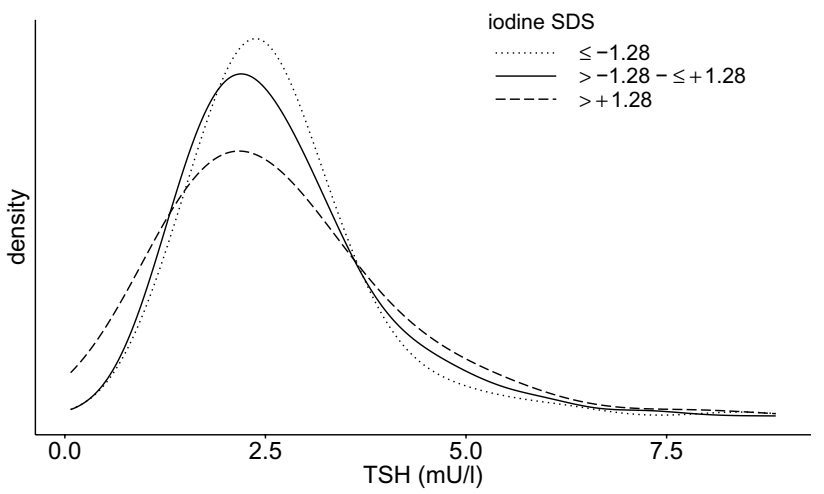

Fig. 3 TSH distribution in high-, medium- and low- spot urine iodine groups. TSH (thyrotropin) distribution in three different groups [small dots: individuals with low spot urine iodine $(<-1.28$ SDS), continuous line: individuals with medium spot urine iodine $(-1.28$ to +1.28 SDS), broad dots: individuals with high spot urine iodine $(>+1.28$ SDS)]. TSH is slightly shifted towards right side in individuals with lower iodine excretion

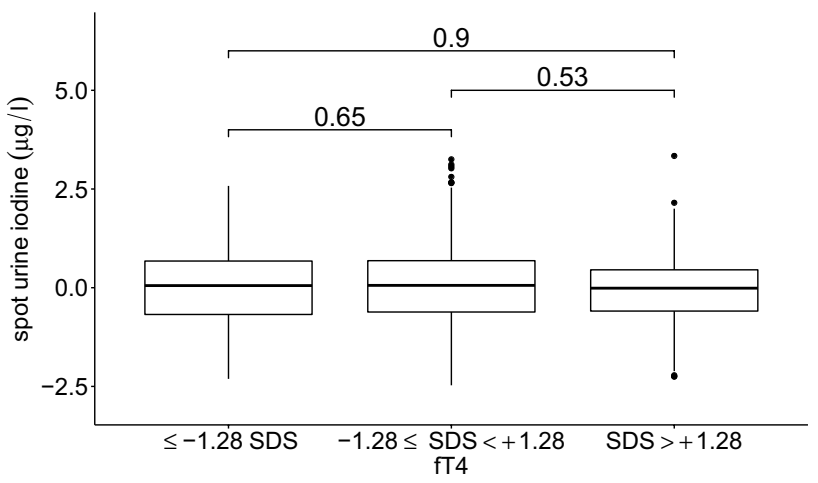

Fig. 4 Spot urine iodine in high-, middle- and low-FT4 groups. Participants were separated into three groups based on FT4 (free thyroxine) level $(<-1.28 \mathrm{SDS},-1.28$ to $+1.28 \mathrm{SDS},>+1.28 \mathrm{SDS})$ and their spot urine levels compared. The numbers on the bars indicate the significance level. Individuals with different FT4 levels presented no significant difference in iodine excretion

\section{lodine deficiency and thyroid autoantibodies}

Levels of thyroid antibodies (TPO-Ab and TG-Ab) were measured in all subjects (data not shown). The antibody values demonstrated very little in the way of age-dependent variation during childhood and adolescence. Nor were there significant correlations for TPO-Ab or TG-Ab and SUIC. Furthermore, a comparison of the highest and the lowest iodine tertiles produced comparable SUIC levels ( $p>0.05)$. 


\section{Discussion}

\section{Spot urine iodine levels}

The first stated aim of our study was to investigate the distribution of SUIC values for a typical cohort of healthy, Central European children and adolescents without chronic or acute disease measured according to the WHO recommendations (Table 1; Fig. 1). Surprisingly, more than half the SUIC values for our cohort were below the WHO recommended median of $>100 \mu \mathrm{g} / \mathrm{L}$, with values for $61.39 \%$ of the boys and $65.91 \%$ of the girls below this target. Additionally, the percentages of boys $(20.79 \%)$ and girls $(26.52 \%)$ with SUIC $<50 \mu \mathrm{g} / \mathrm{L}$ were higher than the $20 \%$ target figure indicated in the WHO recommendations. The reasons for such a conspicuous undershooting of the WHO targets remain to be debated. Despite many efforts to obtain an representative distribution of data our study population shows a bias towards a higher educational and socioeconomic status what may be an important limitation $[19,20]$. Our samples were taken in the morning and in fasting state in accordance with WHO recommendations. Therefore, our data are comparable to other worldwide surveys about iodine distribution in urine [2, 7, 12]. In line with other surveys, our data summarize a negative trend in iodine supply for Central Europe in the last 20 years. In 1999, a nationwide survey in healthy German 6- to 12-year-old school children reported a suboptimal iodine intake in 27\% [13]. Another nationwide study disclosed that $41 \%$ of children and adolescents revealed a suboptimal iodine intake between 2003 and 2006 [12]. In the same period, the DONALD study from the area of Dortmund in Western Germany described a significant decrease of iodine excretion by approximately $1 \mu \mathrm{g} /$ day per year. A lower use of iodized salt in industrial food production was discussed as a potential reason for this observation [26, 27].

The highest SUIC values were observed in children in their first year of life. These high values of infants may be explained by higher iodine intake during pregnancy and breastfeeding. Both of these periods are characterized by an increased need for iodine, vitamins and other micronutrients and both the WHO and the American Academy of Pediatrics recommend supplementation of these substances [28-30]. An increased iodine intake may be attributable to mineral supplements, micronutrient-enriched breast milk and/or enriched formula. It is, therefore, likely that the high SUIC values in the first year of life are the result of increased intake. This hypothesis is supported by the observation that the majority of the subjects in our cohort with excessive values for SUIC were less than one year of age. During early childhood, SUIC levels were decreasing and thereafter remained at a relatively constant level with a small peak during puberty. Such a variance in SUIC could be probably caused by a change in dietary habits [31]. Previous studies described a significant gender difference in SUIC levels, with higher values in boys [32]. We could not confirm this finding in our cohort.

It is important to remember that iodine in urine has a short half-life after ingestion. About $90 \%$ of the iodine is eliminated within 24-48 $\mathrm{h}$ after intake [15]. Measurements of iodine excretion in patients with radioiodine therapy revealed that after admission, $66 \%$ of iodine could be detected in urine after $24 \mathrm{~h}, 87 \%$ after $48 \mathrm{~h}$ and $99 \%$ after $120 \mathrm{~h} \mathrm{[33].} \mathrm{Therefore,} \mathrm{the} \mathrm{individual} \mathrm{iodine} \mathrm{urine} \mathrm{concentra-}$ tion only reflects iodine ingested in the most recent hours or days. To overcome this issue, some authors suggest measuring SUIC after multiple sampling or in $24 \mathrm{~h}$-pooled samples $[34,35]$. Furthermore, in terms of SUIC values, repeated $24 \mathrm{~h}$-sampling over a number of months is more reproducible, whereas a repeated collection of spot urine produces greater variation [36]. The most important advantage of spot urine collection vs. $24 \mathrm{~h}$ urine sampling is its practicability. Even the WHO recommends spot urine measurements because only small amounts of urine are required for the SUIC analysis and casual urine specimens are easy to obtain [2]. In large studies, in particular, it is practically impossible to collect $24 \mathrm{~h}$-pooled samples and, in any case, as the number of participants involved in the study increases, the day-to-day and the intra-day variation of SUI levels tends to even out [2]. Moreover, the classification of a cohort as iodine sufficient or insufficient by the measurement of SUIC has been shown to exhibit excellent reproducibility over one month [36, 37]. As such, SUIC measurement is not appropriate for indicating iodine deficiency in a single individual, but it is very useful for comparing different cohorts or monitoring long-term changes.

\section{Creatinine adjusted iodine spot levels}

Published research indicates that, in children, CCUI matches better with $24 \mathrm{~h}$-iodine excretion than uncorrected spot urine values spot urine alone [38]. As described above, we used age- and gender-dependent SDS values for CCUI as creatinine concentration in urine was found to increase noticeably with age. Additionally, the presence of a strong relationship between urine creatinine-SDS and SUIC-SDS implies that hydration status may be an important consideration in the interpretation of iodine data. We, therefore, tested for a possible association between thyroid hormone parameters and both SUIC-SDS and CCUI-SDS. However, it should be noted that the use of CCUI has two important limitations. First, creatinine excretion depends on the individual's muscle mass and nutritional status. Compared to well-nourished children, children suffering from malnourishment tend to 
have lower serum creatinine levels [39]. In this respect, creatinine-correction does not appear to be helpful, especially when comparing cohorts across different regions of the world. Second, creatinine in children is strongly agedependent, whereas, as we have seen, iodine levels in our study demonstrated only a marginal degree of age dependency. As such, age has a much higher influence on the SUIC/ creatinine-ratio than the iodine levels themselves. In consequence, age-adjusted CCUI-SDS values would be required for the statistical investigation of iodine data in different cohorts. It is also, therefore, mandatory that there be a large number of participants in each age group. Creatinine adjustment, however, may introduce an additional bias into the data. It is, therefore, not recommended when measuring iodine or other trace elements in urine [40]. The WHO uses SUIC measurements only, and describes the iodine to creatinine ratio as "cumbersome, expensive and unnecessary" [2]. In our cohort, the correlation between CCUI-SDS and SUIC-SDS was relatively weak. The reason is that creatinine in urine has a high impact on SUIC. Our conclusion is, therefore, that these parameters measure two different traits. The calculation of CCUI can give additional information about a cohort but in our study neither SUIC nor CCUI were associated with the thyroid function.

\section{lodine deficiency and thyroid parameters: TSH, FT3 and FT4, and thyroid autoantibodies}

Because SUIC levels in our cohort were unexpectedly low and clearly below the WHO recommendation, the question arises whether or not the inferred iodine deficiency was associated with features of an altered thyroid function. Concentrations of thyroid parameters presented a typical age-dependent distribution consistent with findings from other studies and as discussed above [41]. It is important to underline that all the children and adolescents included in our cohort were clinically healthy. Surprisingly, we were able to show that, despite the low SUIC values, there was no indication of significant impairment of thyroid function biomarkers in our cohort. Even if we adjusted iodine levels for hydration status, there was no detectable correlation with thyroid hormone data. Furthermore, the children with increased or decreased TSH levels (3.7\%) showed iodine concentrations similar to those for the whole cohort. In the literature, a clear inverse relationship has been described between median SUIC and the prevalence of goiter in children as identified using ultrasound [42]. Where comparisons have been carried out between cases with iodine uptake of $<50 \mu \mathrm{g} / \mathrm{L}$, and cases of iodine uptake of $>100 \mu \mathrm{g} / \mathrm{L}$, an increased prevalence of goiter has been observed in the $<50 \mu \mathrm{g} / \mathrm{L}$ group. However, the data relating to changes in thyroid hormone parameters in cases of altered SUIC are inconsistent. A positive association with
TSH has been described for high SUIC values [43]. It has also been shown that a higher iodine supply in a cohort can raise the levels of TSH reference ranges [44]. However, other authors have reported finding no difference in thyroid hormone parameters when comparing groups of patients with low $(<50 \mu \mathrm{g} / \mathrm{L})$ as compared to high SUIC $(>200 \mu \mathrm{g} / \mathrm{L})$ values $[45,46]$.

The WHO determined the recommended daily intake of iodine using a calculation of intake in healthy individuals combined with a body of experimental data [47]. The relationship between the daily intake and SUI concentration was based mostly on the hypothesis that an increased supply via nutrition can be absorbed and eliminated within a short time. A steady-state condition had already been demonstrated experimentally [48, 49]. However, no exact SUIC level has previously been identified, on the basis of clinical studies, as a critical threshold for subsequent thyroid dysfunction. Given that our clinically healthy cohort had an insufficient iodine intake according to the WHO recommendation it would appear that these recommended levels are higher than those at which a clinical threshold of this sort would be set. As mentioned above, the WHO suggested the use of spot urine for the ascertainment of SUIC data. Due to the large day-to-day and within-subject variance of iodine levels, there is a possibility of overestimating the number of persons with deficiency or excessive intake. Other methods have been proposed for calculating the true prevalence of deficiency/excess, such as the EAR/UL method [50].

Additionally, we investigated the relationship between SUIC values and levels of thyroid autoantibodies. It has been suggested, somewhat controversially, that higher iodine intake can induce autoimmune thyroiditis [51-53]. In our cohort, autoantibody levels of subjects with relatively high SUIC values were comparable with those in subjects with low SUIC values.

In summary, we investigated spot urine iodine concentration in clinically healthy children and adolescents. Our results were interpreted with reference to WHO recommendations and revealed SUIC values clearly below the recommended levels. However, low SUIC values in our cohort were not associated with impaired thyroid function. Our results suggest that the parameters used to define iodine deficiency for clinical applications need to be revisited.

Acknowledgements Open Access funding provided by Projekt DEAL. This work was supported by LIFE Child, which is financed by the excellence initiative of the Saxony Ministry of Science and Art, Saxony, Germany and the European Regional Development Fund of the European Union. We thank all participants of the LIFE Child study and their families and all staff members of both the study clinic and the analyzing laboratory.

Funding This study was supported by the Saxon State Ministry of Science and Art in context of the LIFE Function program. 


\section{Compliance with ethical standards}

Conflict of interest All authors declare that there is no conflict of interest that could be perceived as prejudicing the impartiality of the research reported.

Open Access This article is licensed under a Creative Commons Attribution 4.0 International License, which permits use, sharing, adaptation, distribution and reproduction in any medium or format, as long as you give appropriate credit to the original author(s) and the source, provide a link to the Creative Commons licence, and indicate if changes were made. The images or other third party material in this article are included in the article's Creative Commons licence, unless indicated otherwise in a credit line to the material. If material is not included in the article's Creative Commons licence and your intended use is not permitted by statutory regulation or exceeds the permitted use, you will need to obtain permission directly from the copyright holder. To view a copy of this licence, visit http://creativecommons.org/licenses/by/4.0/.

\section{References}

1. EFSA (2014) Scientific opinion on dietary reference values for iodine. EFSA J 12(5):3660. https://doi.org/10.2903/j. efsa.2014.3660

2. WHO (2007) Assessment of iodine deficiency disorders and monitoring their elimination: a guide for programme managers, 3rd edn. WHO Press, Geneve

3. Deutsche Gesellschaft für Ernährung e.V (2018) Deutsche Gesellschaft für Ernährung e.V.-Jod. In: Referenzwerte Iod. https://www.dge.de/wissenschaft/referenzwerte/jod. Accessed 21 Oct 2019

4. Zimmermann MB, Jooste PL, Pandav CS (2008) Iodine-deficiency disorders. Lancet 372:1251-1262. https://doi.org/10.1016/S0140 -6736(08)61005-3

5. de Benoist B, McLean E, Andersson M, Rogers L (2008) Iodine deficiency in 2007: global progress since 2003. Food Nutr Bull 29:195-202. https://doi.org/10.1177/156482650802900305

6. Andersson M, Karumbunathan V, Zimmermann MB (2012) Global iodine status in 2011 and trends over the past decade. J Nutr 142:744-750. https://doi.org/10.3945/jn.111.149393

7. Zimmermann MB, Andersson M (2012) Update on iodine status worldwide. Curr Opin Endocrinol Diabetes Obes 19:382-387. https://doi.org/10.1097/MED.0b013e328357271a

8. Serafico ME, Perlas LA, Ulanday JRC et al (2019) Current state of iodine nutrition in Filipino school-aged children. Nutrition 58:134-139. https://doi.org/10.1016/j.nut.2018.06.023

9. Völzke H, Erlund I, Hubalewska-Dydejczyk A et al (2018) How do we improve the impact of iodine deficiency disorders prevention in Europe and beyond? Eur Thyroid J 7:193-200. https://doi. org/10.1159/000490347

10. Mazzarella C, Terracciano D, Di Carlo A et al (2009) Iodine status assessment in Campania (Italy) as determined by urinary iodine excretion. Nutrition 25:926-929. https://doi.org/10.1016/j. nut.2009.01.020

11. De Benoist B, Andersson M, Egli IM et al (2004) Iodine status worldwide: WHO global database on iodine deficiency. https:// apps.who.int/iris/bitstream/handle/10665/43010/9241592001.pdf. Accessed 21 Oct 2019

12. Thamm M, Ellert U, Thierfelder W et al (2007) Jodversorgung in Deutschland. Bundesgesundheitsblatt Gesundheitsforsch Gesundheitsschutz 50:744-749. https://doi.org/10.1007/s0010 3-007-0236-4
13. Hampel R, Beyersdorf-Radeck B, Below H et al (2001) Jodidurie bei Schulkindern in Deutschland 1999 im Normbereich. Med Klin 96:125-128. https://doi.org/10.1007/PL0000218414

14. Zimmermann MB, Andersson M (2012) Assessment of iodine nutrition in populations: past, present, and future. Nutr Rev 70:553-570. https://doi.org/10.1111/j.1753-4887.2012.00528.x

15. Vanderpump MP (2017) Epidemiology of iodine deficiency. Minerva Med 108:116-123. https://doi.org/10.23736/S0026 $-4806.16 .04918-1$

16. Duntas LH (2015) The role of iodine and selenium in autoimmune thyroiditis. Horm Metab Res 47:721-726. https://doi. org/10.1055/s-0035-1559631

17. Palaniappan S, Shanmughavelu L, Prasad HK et al (2017) Improving iodine nutritional status and increasing prevalence of autoimmune thyroiditis in children. Indian J Endocrinol Metab 21:85-89. https://doi.org/10.4103/2230-8210.195996

18. Quante M, Hesse M, Döhnert M et al (2012) The LIFE child study: a life course approach to disease and health. BMC Public Health 12:1021. https://doi.org/10.1186/1471-2458-12-1021

19. Poulain T, Baber R, Vogel M et al (2017) The LIFE Child study: a population-based perinatal and pediatric cohort in Germany. Eur J Epidemiol. https://doi.org/10.1007/s10654-016-0216-9

20. Ittermann $\mathrm{T}$, Johner $\mathrm{S}$, Below $\mathrm{H}$ et al (2018) Interlaboratory variability of urinary iodine measurements. Clin Chem Lab Med 56:441-447. https://doi.org/10.1515/cclm-2017-0580

21. Pino S, Fang SL, Braverman LE (1996) Ammonium persulfate: a safe alternative oxidizing reagent for measuring urinary iodine. Clin Chem 42:239-243

22. Kratzsch J, Schubert G, Pulzer F et al (2008) Reference intervals for TSH and thyroid hormones are mainly affected by age, body mass index and number of blood leucocytes, but hardly by gender and thyroid autoantibodies during the first decades of life. Clin Biochem 41:1091-1098. https://doi.org/10.1016/j. clinbiochem.2008.04.007

23. Vogel M, Kirsten T, Kratzsch J et al (2017) A combined approach to generate laboratory reference intervals using unbalanced longitudinal data. J Pediatr Endocrinol Metab JPEM 30:767-773. https://doi.org/10.1515/jpem-2017-0171

24. Team RDC (2018) R: a language and environment for statistical computing. $\mathrm{R}$ foundation for statistical computing. https://www. gbif.org/tool/81287/r-a-language-and-environment-for-statistica 1-computing. Accessed 21 Oct 2019

25. Bissinger K, Busl L, Dudenhöfer C et al (2018) Repräsentative Markterhebung zur Verwendung von Jodsalz in handwerklich und industriell gefertigten Lebensmitteln. https://service.ble. de/ptdb/index2.php?detail_id=151927\&site_key=141\&stich $\mathrm{w}=$ Jodsalz\&zeilenzahl_zaehler $=2 \& \mathrm{pId}=151927 \& \mathrm{dId}=45426$ 00. Accessed 20 Apr 2020

26. Johner S, Thamm M, Nöthlings U et al (2013) Iodine status in preschool children and evaluation of major dietary iodine sources: a German experience. Eur J Nutr 52:1711-1719. https ://doi.org/10.1007/s00394-012-0474-6

27. Khayat S, Fanaei H, Ghanbarzehi A (2017) Minerals in pregnancy and lactation: a review article. J Clin Diagn Res JCDR 11:QE01-QE05. https://doi.org/10.7860/JCDR/2017/28485 .10626

28. Kaiser L, Allen LH, American Dietetic Association (2008) Position of the American Dietetic Association: nutrition and lifestyle for a healthy pregnancy outcome. J Am Diet Assoc 108:553-561. https://doi.org/10.1016/j.jada.2008.01.030

29. Council on Environmental Health, Rogan WJ, Paulson JA et al (2014) Iodine deficiency, pollutant chemicals, and the thyroid: new information on an old problem. Pediatrics 133:1163-1166. https://doi.org/10.1542/peds.2014-0900

30. Watutantrige Fernando S, Cavedon E, Nacamulli D et al (2016) Iodine status from childhood to adulthood in females living in 
North-East Italy: iodine deficiency is still an issue. Eur J Nutr 55:335-340. https://doi.org/10.1007/s00394-015-0853-x

31. Als C, Keller A, Minder C et al (2000) Age- and gender-dependent urinary iodine concentrations in an area-covering population sample from the Bernese region in Switzerland. Eur J Endocrinol 143:629-637. https://doi.org/10.1530/eje.0.1430629

32. Demir M, Parlak Y, Cavdar I et al (2013) The evaluation of urine activity and external dose rate from patients receiving radioiodine therapy for thyroid cancer. Radiat Prot Dosim 156:25-29. https:// doi.org/10.1093/rpd/nct036

33. Remer T, Fonteyn N, Alexy U, Berkemeyer S (2006) Longitudinal examination of 24-h urinary iodine excretion in schoolchildren as a sensitive, hydration status-independent research tool for studying iodine status1-3. Am J Clin Nutr 83:639-646

34. König F, Andersson M, Hotz K et al (2011) Ten repeat collections for urinary iodine from spot samples or 24-hour samples are needed to reliably estimate individual iodine status in women. J Nutr 141:2049-2054. https://doi.org/10.3945/jn.111.144071

35. Chen W, Wu Y, Lin L et al (2016) 24-hour urine samples are more reproducible than spot urine samples for evaluation of iodine status in school-age children. J Nutr 146:142-146. https://doi. org/10.3945/jn.115.215806

36. Charlton KE, Ware LJ, Baumgartner J et al (2018) Iodine status assessment in South African adults according to spot urinary iodine concentrations, prediction equations, and measured 24-h iodine excretion. Nutrients 10:736. https://doi.org/10.3390/nu100 60736

37. Montenegro-Bethancourt G, Johner SA, Stehle P et al (2015) Iodine status assessment in children: spot urine iodine concentration reasonably reflects true twenty-four-hour iodine excretion only when scaled to creatinine. Thyroid Off J Am Thyroid Assoc 25:688-697. https://doi.org/10.1089/thy.2015.0006

38. Hari P, Bagga A, Mahajan P, Lakshmy R (2007) Effect of malnutrition on serum creatinine and cystatin $C$ levels. Pediatr Nephrol 22:1757-1761. https://doi.org/10.1007/s00467-007-0535-x

39. Hoet P, Deumer G, Bernard A et al (2016) Urinary trace element concentrations in environmental settings: is there a value for systematic creatinine adjustment or do we introduce a bias? J Expo Sci Environ Epidemiol 26:296-302. https://doi.org/10.1038/ jes.2015.23

40. Gesundheitsberichterstattung des Bundes (2009) Bevölkerungsbezogene Verteilungswerte ausgewählter Laborparameter aus der Studie zur Gesundheit von Kindern und Jugendlichen in Deutschland (KiGGS). https://www.rki.de/DE/Content/Gesun dheitsmonitoring/Gesundheitsberichterstattung/GBEDownloa dsB/KiGGS_Laborparameter.pdf?__blob=publicationFile . Accessed 21 Oct 2019

41. Delange F, Benker G, Caron P et al (1997) Thyroid volume and urinary iodine in European schoolchildren: standardization of values for assessment of iodine deficiency. Eur J Endocrinol 136:180-187. https://doi.org/10.1530/eje.0.1360180

42. Kim HI, Oh H-K, Park SY et al (2017) Urinary iodine concentration and thyroid hormones: Korea National Health and Nutrition Examination Survey 2013-2015. Eur J Nutr. https://doi. org/10.1007/s00394-017-1587-8

43. Ittermann T, Khattak RM, Nauck M et al (2015) Shift of the TSH reference range with improved iodine supply in Northeast Germany. Eur J Endocrinol 172:261-267. https://doi.org/10.1530/ EJE-14-0898

44. Soldin OP, Tractenberg RE, Pezzullo JC (2005) Do thyroxine and thyroid-stimulating hormone levels reflect urinary iodine concentrations? Ther drug Monit 27:178-185. https://doi.org/10.1097/01. ftd.0000149954.20089.0b

45. Johner SA, Thamm M, Stehle P et al (2014) Interrelations between thyrotropin levels and iodine status in thyroid-healthy children. Thyroid 24:1071-1079

46. FAO/WHO (2001) Joint FAO/WHO expert consultation on human vitamin and mineral requirements. Vitamin and mineral requirements in human nutrition. http://www.fao.org/3/a-y2809e.pdf. Accessed 20 June 2019

47. de la Hunt M (1996) Diuresis and voiding pattern in healthy schoolchildren. J Pediatr Surg 31:783-789. https://doi. org/10.1016/S0022-3468(96)90462-5

48. Institute of Medicine (US) — Food and Nutrition Board (2001) Dietary reference intakes for vitamins $\mathrm{A}$ and $\mathrm{K}$, iodine and other minerals. National Academic Press, Washington DC

49. Zimmermann MB, Hussein I, Al Ghannami S et al (2016) Estimation of the prevalence of inadequate and excessive iodine intakes in school-age children from the adjusted distribution of urinary iodine concentrations from population surveys. J Nutr 146:12041211. https://doi.org/10.3945/jn.115.229005

50. Miranda DMC, Massom JN, Catarino RM et al (2015) Impact of nutritional iodine optimization on rates of thyroid hypoechogenicity and autoimmune thyroiditis: a cross-sectional, comparative study. Thyroid Off J Am Thyroid Assoc 25:118-124. https://doi. org/10.1089/thy.2014.0182

51. Bliddal S, Boas M, Hilsted L et al (2017) Increase in thyroglobulin antibody and thyroid peroxidase antibody levels, but not preterm birth-rate, in pregnant Danish women upon iodine fortification. Eur J Endocrinol 176:603-612. https://doi.org/10.1530/ EJE-16-0987

52. Zimmermann MB, Boelaert K (2015) Iodine deficiency and thyroid disorders. Lancet Diabetes Endocrinol 3:286-295. https://doi. org/10.1016/S2213-8587(14)70225-6

53. Max-Rubner-Institut (2008) Ergebnisbericht Nationale Verzehrstudie Teil 2. https://www.mri.bund.de/fileadmin/MRI/Insti tute/EV/NVSII_Abschlussbericht_Teil_2.pdf. Accessed 20 June 2019 